\title{
CAN WE INTEND THE PAST?
}

\author{
Oded Na'aman
}

$\prod$

N THE BURGEONING LITERATURE on the rationality of regret, Jay Wallace's The View from Here has played an important role. It is a book full of provocative and gripping ideas. One such idea concerns the way in which our love and attachment may, and often do, implicate us in the wrongs and evils of the past. In particular, Wallace argues that our love and attachment involve something like a willingness to bring about the necessary conditions for the existence of their objects, even when those conditions involve wrongs and evils that we should not be willing to bring about. Therefore, the persons and things that are most important to us implicate us in their morally dubious genealogy.

Wallace calls the backward unfurling of intention due to one's present attachments the affirmation dynamic. Some have found the affirmation dynamic plausible and offered further defense of it. ${ }^{1}$ Others have found plausible a qualified version of the affirmation dynamic. ${ }^{2}$ I argue that the affirmation dynamic is impossible, at least as Wallace construes it. In particular, I argue that the idea that we may have intention-like attitudes about the past is fundamentally confused. It betrays a misguided conception of retrospection as involving a choice between courses of history. As an alternative to this timeless conception of retrospection, I briefly propose that retrospection is diachronic: it begins after the moment of choice or action has passed and unfolds over time and in accordance with its own standards of appropriateness. Contrary to Wallace's view, affirming and regretting the past involve no longer viewing it as a matter of choice.

We may regret the past in various ways. However, according to Wallace, all-in regret involves an on-balance preference that the object of regret did not occur. ${ }^{3}$ Wallace's counterpart to all-in regret is on-balance affirmation. On-balance affir-

1 Kolodny, "Dynamics of Affirmation."

2 Nagel, "An Invitation to Hand-Wringing”; Munoz-Dardé, "Puzzles of Regret."

3 Wallace, The View from Here, 55. 
mation involves an on-balance preference that the object of affirmation did occur. In regretting or affirming (I henceforth drop the qualifications "all-in" and "on-balance") we settle the question: "Would we, knowing what we now know about how things have since played out, bring it about that things were otherwise in the respect that we are focusing on, if it were in our power to do so?"4 The attitudes of regret and affirmation are therefore like conditional intentions. They involve a commitment to doing something in certain conditions. These attitudes are only like conditional intention because the conditions they invoke will never obtain and therefore these attitudes will never lead to action. ${ }^{5}$

Affirmation of one object, according to Wallace, has a way of spreading to others. The people we love and the projects to which we are attached give us powerful reasons to affirm them. ${ }^{6}$ The affirmation that is called for with regard to objects of love and attachment is especially demanding, for it involves being "glad on balance that those objects are part of the history of the world, taking into account the totality of things that they involved."7 Crucially, Wallace claims that this unconditional affirmation entails a commitment to affirming "the historical conditions that were necessary for the existence of the thing that one affirms." ${ }^{8}$ Such affirmation is incompatible with regret, and therefore our unconditional affirmation of the objects of our attachment precludes regretting any of the necessary conditions (whether causal or constitutive) for their existence. This is the affirmation dynamic.

The affirmation dynamic leads to serious trouble. The causal lineage that made one's objects of attachment possible is bound to involve some deeply regrettable events somewhere along the way. I, for one, can confidently say that neither my existence nor the existence of most of the people I love would have been possible if it were not for the occurrence of the Holocaust. Similar concerns arise with regard to many of the projects and activities we cherish. For instance, Wallace remarks that the readers of his book are likely to be attached to academic philosophy, itself a "bourgeois pursuit" made possible by serious past (and present) injustice. Once we consider the intricate courses of history that made the objects of our attachments possible, none of us remain unscathed by their sordid past.

4 Wallace, The View from Here, 62

$5 \quad$ Wallace, The View from Here, 55-57.

$6 \quad$ Wallace, The View from Here, 75.

7 Wallace, The View from Here, 75.

8 Wallace, The View from Here, 75. 
We are committed to willing those evils and wrongs without which the objects of our attachments would not have existed.

Thomas Nagel accepts the affirmation dynamic but in light of its disturbing upshots claims it should be contained: "our affirmation of anything ... is bounded by a statute of limitations on its reach into the past. We can take much about the world that we have not created, good and bad, as simply given, and limit our affirmations and regrets to what is downstream from that." Niko Kolodny defends Wallace's unbounded affirmation dynamic by arguing against Nagel's proposed cutoff point. ${ }^{10}$ Why does the affirmation of an object of attachment commit us to affirming all the necessary conditions for its existence? Kolodny argues this is due to the principle of instrumental rationality, according to which if one intends an end one is committed to intending the necessary means to it.

Let me briefly rehearse Kolodny's argument. As Wallace argues, and both Kolodny and Nagel accept, by affirming an object of our attachment we intend to bring it about if we could. If a past wrong was necessary for the existence of the object of our attachment, then if we could bring it about this wrong would be a necessary means for the existence of the object of our attachment. Given that we intend to bring about the object of our attachment, the principle of instrumental rationality commits us to intending to bring about the necessary means to it, including the past wrong. It does not matter where on the axis of time the past wrong lies; what matters for our commitment to affirming it is only that it was necessary for our end, that is, for the existence of the object of our attachment. Thus, instrumental rationality leads us from affirming the object of our attachment to affirming all of its necessary conditions. ${ }^{11}$

Kolodny's argument is valid, but it relies on a premise that both Nagel and Kolodny accept without question: that regret and affirmation are intention-like attitudes. If this premise is false, and regret and affirmation should not be construed as intention-like attitudes, then it is also false that by failing to affirm the necessary conditions for the existence of one's object of affirmation one fails to intend the necessary means for one's end. The affirmation dynamic would be blocked right from the start. The principle of instrumental rationality does not plausibly apply to wishes, for example, because they do not relate to action as intentions do.

9 Nagel, "An Invitation to Hand-Wringing," 25-26.

10 Kolodny, "Dynamics of Affirmation."

11 Kolodny, "Dynamics of Affirmation," 772. 
One crucial element of intention, conditional or not, is that from the agent's point of view it might lead to action. In other words, one cannot intend what one takes to be impossible. ${ }^{12}$ If I went to sleep early last night then I cannot go to sleep early last night again; if I did not go to sleep early last night then I can never do so. But if I believe that it is impossible for me to go to sleep early last night, then it is impossible for me to intend to go to sleep early last night, even though it is perfectly possible for me to regret not doing so or to be glad I did. ${ }^{13}$ Regret and affirmation cannot be like intending a past occurrence since they are possible when the latter is not.

Wallace, however, does not suggest that in regretting or affirming a past occurrence we actually intend to change or repeat that very same occurrence. Rather, he argues that in regretting or affirming a past occurrence we intend to change or repeat it if we could. Wallace may therefore grant that if one believes [ $\phi$-ing in $c]$ is impossible then it is impossible that one intends [to $\phi$ in $c]$. And yet Wallace may still insist that when one believes $[\phi$-ing in $c]$ is impossible, one may consistently believe that $[\phi$-ing if $c]$ is possible and therefore intend [to $\phi$ if $c]$. The reasoning might be the following: if $c$ is impossible, then it will never be the case that $c$ obtains and I do not $\varphi$, so my success at $[\phi$-ing if $c]$ is guaranteed. The impossibility of the antecedent guarantees the satisfaction of the intended conditional.

This maneuver, however, is too successful. Since $[\phi$-ing if $c]$ is trivially satisfied due to the impossibility of $c$, there is nothing I need to do in order to $[\phi$ if $c$ ]. In particular, I do not ever need to intend to $\phi$. My conditional intentions are empty when I take them to be trivially realized. Consider my intention to run in the street naked if $2+2=5$. Since I believe the antecedent impossible, I may intend never to run in the street naked and still coherently intend to do so if $2+2=5$. Whether because I cannot intend what I take to be impossible or because I believe the condition of my intention is impossible, I do not intend anything at all. As I said, it is crucial for intention that from the agent's point of view it might lead to action. ${ }^{14}$

By contrast, it is precisely the impossibility of action that makes room for regret. It is distinctive of regret that it is directed toward settled facts. Even if we can act to mitigate the negative consequences of a regrettable choice or compen-

Davidson, "Intending," 100-1. For the purposes of this discussion, I use "believe impossible" and "take to be impossible" interchangeably.

Note that I might falsely believe it possible for me to go to sleep early last night, in which case it would be possible for me to intend to do so. We cannot do what is impossible, but we can intend it as long as we believe it possible.

Hills ("Hindsight," 11-12) makes a similar point. 
sate those harmed by it, our regret is intelligible only on the assumption that we take the choice itself to be irreversible. We can wish we did not make it, or wish we could go back and choose differently, but we can intend neither. To say that affirmation and regret are different from conditional intentions only in that their conditions are taken by the agent to be impossible is to say that affirmation and regret are nothing like conditional intentions.

I said earlier that many of the people I love would not have existed were it not for the occurrence of the Holocaust. Clearly, it would be insane of me to intend the occurrence of the Holocaust for the sake of the individuals whose existence was made possible by it. But why would it be insane? Wallace and Kolodny are impressed by the fact that I cannot justify causing so much evil and suffering for the sake of my few friends and family members. But to stop here would be to overlook a further aspect of my would-be insanity, namely, that by intending to bring about the Holocaust for the sake of the existence of my loved ones I would be treating the occurrence of the Holocaust as unsettled. That is, by intending to bring about the Holocaust I would commit myself to the possibility of actually bringing about the Holocaust. I would thereby fail to appreciate the fact that the Holocaust is an event that lies in the past and whose occurrence I can do absolutely nothing about. A willingness to bring about an event like the Holocaust is morally insane; a willingness to bring about the Holocaust is plain insane.

The idea that we can have intentions about the past can seem plausible if we conceive of retrospection as a choice between courses of history. Such a choice would aspire to take into account the totality of occurrences in each possible chain of events to determine which course of history should be chosen on balance. ${ }^{15}$ On this timeless conception of retrospection, as we might call it, our regret and affirmation reflect where we happen to be in history, but they are justified by a more fundamental choice that is not itself expressive of any course of history. Our location in time should not impact our evaluation of each course of history taken as a whole. Intending a past occurrence does not seem insane since the intention is expressive of one's endorsement of an entire course of history considered from an atemporal point of view. In light of this model of retrospection, our commitment to people with whom we happen to coexist at the expense of those who existed before us seems difficult to justify. ${ }^{16}$

Again, Hills makes a similar point ("Hindsight," 19). coexist with us over their nonexistence. However, his claim seems difficult to square with 
Wallace is not alone in implicitly assuming such a timeless conception of retrospection. Kieran Setiya recently discussed retrospection as a preference between "world-histories." ${ }^{17}$ And John Rawls relies on this model of retrospection for his view of rational regret. According to Rawls, regret about one's choices is rational when the choices were not part of one's rational life plan, understood as the plan "that would be decided upon as the outcome of careful reflection in which the agent reviews, in the light of all the relevant facts, what it would be like to carry out these plans and thereby ascertained the course of action that would best realize his more fundamental desires." ${ }^{18}$ According to Rawls, in making a particular choice a rational person endorses a life plan of which the choice is a component; correspondingly, in regretting a particular choice a rational person disowns a life plan of which the choice is a component. In short, for Rawls, every rational choice is a choice of a whole life plan, which spans backward and forward in time. Therefore, in intending a specific choice a rational agent intends its rational future as well as its rational past.

A focus on the choice- and action-guiding roles of practical reason might have led philosophers to endorse a timeless conception of retrospection: a conception of retrospection as a choice of history. But retrospection should not be construed as a futile attempt to undo or redo history as viewed from a point of view outside of it. Rather, retrospection occurs when the past is already settled and the space for intention is closed; it occurs in time and over time and may involve various complicated emotions and thoughts.

For example, a diachronic model of retrospection differs from a timeless model of retrospection in making room for non-comparative preferences or wishes. In a choice situation, preferences are naturally interpreted as comparative: a preference against one option tells in favor of the alternative, and vice versa. Accordingly, if we model retrospection on a choice between courses of history, then a preference against one course of history tells in favor of another. That this model is mistaken is demonstrated by the fact that we often have rational non-comparative preferences about the past. When I order the burger but

his timeless conception of retrospection, in which our attitudes toward the past are determined by our overall evaluations of possible courses of history. Setiya's claim about preferences regarding coexisters may therefore seem like an ad hoc exception made to accommodate intuitions that tell against his timeless conception of retrospection.

Setiya, “The Ethics of Existence," 294, and “Retrospection," 10.

Rawls, A Theory of Justice, 415-16. 
later wish I had the schnitzel instead, I have a comparative counterfactual wish, but if the burger gave me food poisoning I might simply wish I did not have it without having any replacement in mind, in which case I have a non-comparative counterfactual wish. Preferring or wishing that things were otherwise does not rationally commit us to preferring the most likely alternative, or any specific alternative at all for that matter.

Upon reading the memoirs of Jean Améry, Primo Levi, or Robert Antelme, I am horrified by the events of the Holocaust and wish with all my heart that they did not occur. But I do not thereby commit myself to preferring any specific alternative history, and I certainly do not commit myself to preferring a history in which my loved ones did not exist. Appropriate retrospection might preclude a consistent view of our preferred course of history. This is an important lesson from Wallace's affirmation dynamic: there is probably no causally possible course of history that would satisfy all our most fervent retrospective preferences-no one course of history that we favor over all others given the totality of things it includes. But this is as it should be given that history is not, for us, a matter of choice. ${ }^{19}$

Stanford University onaaman@stanford.edu

\section{REFERENCES}

Davidson, Donald. "Intending." In Essays on Actions and Events, 83-102. Oxford: Oxford University Press, 1980.

Hills, David. "Hindsight." Unpublished manuscript.

Kolodny, Niko. "Dynamics of Affirmation." Philosophy and Phenomenological Research 92, no. 3 (May 2016): 771-77.

Munoz-Dardé, Véronique. "Puzzles of Regret." Philosophy and Phenomenological Research 92, no. 3. (May 2016): 778-84.

Nagel, Thomas. "An Invitation to Hand-Wringing." London Review of Books 36, no. 7 (April 3, 2014): 25-26.

Rawls, John. A Theory of Justice. Cambridge, MA: Harvard University Press, 1971. Setiya, Kieran. "The Ethics of Existence." Philosophical Perspectives 28, no. 1 (December 2014): 291-301.

$$
\text { . "Retrospection." Philosophers' Imprint 16, no. } 15 \text { (August 2016): 1-15. }
$$

19 I wish to thank Johann Frick and Jorah Dannenberg for their valuable comments on previous drafts of this paper. 
Wallace, R. Jay. The View from Here: On Affirmation, Attachment, and the Limits of Regret. Oxford: Oxford University Press, 2013. 